\title{
Reengineering of the management processes of information support of heat supplying organizations of heating systems of a city
}

\author{
Natalia Verstina ${ }^{1, *}$ and Evgeny Evseev ${ }^{2}$ \\ ${ }^{1}$ Moscow State University of Civil Engineering, 26, Yaroslavskoye Shosse, 129337, Moscow, Russia \\ ${ }^{2}$ Moscow Institute of Physics and Technology, 9 Institutskiy per., 141701, Dolgoprudny, Moscow \\ Region, Russia
}

\begin{abstract}
Changes in management of the heat-supplying organizations of the modern city determined by development of technologies in this sphere are considered in the article. Three groups of technologies are allocated, the priority of the auxiliary technologies considered is given. The author points out that there is the need of the information support of management of the heating systems management in the city, which need fundamental reconsideration and radical redesign. The additional argument of the need of reengineering of the heat supplying organizations management is the consideration of the results of their activity, connected with considerable thermal losses. The key provisions of the offered measures for reengineering, based on the creation of processes of information support of management "from scratch" are described. Negative changes of the performance of the heating systems of concrete types were estimated q, and thanks to that the new integrated approach to the choice of methods and technical means of diagnostics of engineering systems and analytical dependences of determination of terms of repair were offered. Obtaining of qualitatively new information through reengineering measures for making managerial decisions is considered. Scenarios of prospects of energy industry, which have been differentiated as the most realistic or connected with the risk of increase in the stubborn problems, minimized by reengineering, were analyzed.
\end{abstract}

\section{Introduction}

Nowadays the world practice of management observes some tendencies to changes, which demand not only gradual improvement of activity, but also implementation of measures of breakthrough character. Modern cities development, brings more changes into the quality of environment of the humans, which stimulate carrying out essential transformations in activity of the organizations, operating the city infrastructure facilities, including engineering networks. In the cities of the Russian Federation the heat-supplying organizations (HSO), operating the centralized heating systems, which extent and power is estimated of 40 percent from total of such engineering systems in the world, function for a long time. At the same

*Corresponding author: verstina@mail.ru 
time the problems which are kept in the HSO management amplify and spark fair criticism, both by consumers, in whose structure of payments for utilities payment of heating and hot water supply makes more than a half of the amount, and by the public authorities, regulating large-scale activities for heat supply in the Russian Federation (the share of the heating energy, delivered by the centralized systems, makes $35 \%$ of final consumption of all types of energy in the country).

Some facts, connected with the results of modern HSO management in the Russian Federation are not satisfactory, the situation demands carrying out fundamental reconsideration of the organization of the processes of heating systems maintenance in the city. The most serious are unproductive losses of heat during production (up to 22\%), during transportation heat (up to $25 \%$ ), during consumption (up to $30 \%$ ), percentage is given for the total amount on the corresponding technological repartition of delivery. If the total extent of heating systems in 85 regions of the Russian Federation in two-pipe calculation is about 185 thousand $\mathrm{km}$, according to the expert estimates, at least 48 thousand $\mathrm{km}$ or more than $25 \%$ required replacement. The calculations for acceleration of rates of updating of worn-out heating systems, which have been carried out earlier by experts, were focused on overcoming of the situation, which have been taking place in the country within 5-7 years, while the annual repair of engineering networks is about 7 thousand $\mathrm{km}$. However, the practice has proved, that the operating control system of HSO is not able even to overcome the tendency of the increase of the heating systems wear, besides the information on its actual state is not always formed and used for adoption of efficient managerial decisions. The current situation is, to a certain extent, the consequence of preservation in HSO throughout rather a long time of invariable technological base of heat supply regarding design and constructive solutions, technologies of construction and reconstruction, the technological modes of maintenance and technical means of diagnostics of heating systems.

Rather recently conditions for cardinal changes of the situation were created: the task of activation of the scientific-and-technological development assuming introduction and distribution of the technologies, new to the Russian energy industry, based on the perspective development and results of modern research [1] is set for branches of Russian energy industry at the state level. There is the fair emphasis on the technologies which in modern urban development become the key factor of success in all the spheres of functioning of the megalopolis. The system approach to the differentiation of technologies, offered in the document which allows to expand the tools of ecological management of heat supplying organizations (HSO), integrated with the primary production activity is important. At the same time three types of technologies, in total capable to minimize the adverse effect of the heating systems under maintenance on the environment in urban development are distinguished:

- main technologies providing the main working process;

- auxiliary technologies, for example, technologies of the built-in control systems of functioning of the heating systems providing normal conditions for the realization of the main technology in full accordance with the design and maintenance documents;

- additional technologies, expanding the possibilities of the main technology, for the satisfaction of ecological requirements, improvement of quality of the services, cutting of resources consumption, etc., for example, technologies of information support of management of heat supplying organizations.

The importance of the prospects of improvement of additional technologies in heat supply is determined by the fact that in modern conditions the level of the influence of the main technology on the urban environment and access it on the specific markets of heat which are characterized by territorial fixedness within urban development on which the generating capacities compete greatly depends on them (for example, combined heat-and-power plant and boiler rooms). It is obvious that the predicted changes of technologies will serve as the 
catalyst of changes in management of heat supplying organizations, and some scenarios have been already created by experts [2]. Therefore it is important to define the possibility of effective use of new advantages in management which basis is information support.

Some experience of improvement of management of large-scaled engineering systems of the modern cities in the Russian Federation is indicative for their development in other countries both regarding the saved-up positive practice of management, and from the point of view of identification of problem situations, which solving by methods of reengineering can bring positive results [3].

\section{Materials and methods}

In the previous works, devoted to management of HSO, authors carried out the analysis of processes the heating systems maintenance management in the city which proved that despite the development of various new instruments of management the key matter (providing a control system of information of the required quality) has not received the due solution [4]. Practice demonstrates that all HSO in our country use the approaches to the organization of these auxiliary technologies at heating systems maintenance in the city were never positioned by researchers and managers as an independent subject of the analysis and redesign regarding the organization of the corresponding processes with considerably bigger efficiency. At the same time before introduction of the planned changes of the main and additional technologies due to results of modern researches and perspective developments in the estimated prospect, it is necessary to reconstruct information system of HCO [5] already now cardinally. Moreover, these changes will allow to improve current situation of management considerably. Obtaining new quality of information necessary for decision-making for HSO management, was considered in a certain logic in the assumption that the creation of a new information system is carried out.

The main questions were:

- which information is required from the information system for identification of technical performance of the heating systems under maintenance;

- the choice the complex of methods and diagnostic aids for determining the condition of heating systems, depending on terms of their operation, constructive decisions,

- formation of conditions for identification of sites of the heating systems, which are subject to diagnosing

- redesign of information exchange of divisions and employees of HSO on the basis of the offered data representation forms about technical performance of heating systems.

We will consider more specifically some substantial characteristic of the provisions of reengineering, the used methods and materials given above for their realization.

The carried-out analysis of the reasons has proved that the most essential of them is the group, leading eventually to the emergence of different types of corrosion damages on an external surface of the heating systems surface, to contact of metal elements with the water which is in the environment surrounding them. The operational phase in life cycle of heating systems can be also accompanied by risk factors which serve as the reasons of deterioration in their technical condition. The most dangerous are also the reasons, leading to corrosion processes, but already mainly on an internal surface: for example, existence of a certain amount of oxygen or chlorine in the transported heat carrier. Mainly low-quality materials and products of designs of heating systems which can be complemented also with defects of installation are the reasons of not corrosion damages. Thus, the provided short characteristic of the conducted researches of the reasons of negative events at operation, has proved, that the change of performance of heating systems mostly arise because of corrosion and their manifestation depends on the speed of corrosion processes. This factor defines also mainly and types of the events changing technical conditions of the heating systems under 
maintenance in the wide range - from efficient to disabled, through intermediate states serviceable, faulty which are also options of development of negative consequences of the revealed reasons [6]. As for making managerial decisions it is important to distinguish the aforesaid concepts, which in practice demand some actions of various character, and, which respectively, define distinctions to the choice of methods of diagnostics of technical conditions of the heating systems. Such terms as "properly functioning", "faulty" i are wider, than terms "efficient", "disabled". Examples of their correlation are known, when the efficient heating system performs the set functions on transportation and distribution of heat, but at the same time it is faulty as the efficient condition demands the satisfaction only of those requirements, which provide normal use of engineering system to destination. So, the heating system can be operated and be efficient in the presence of insignificant volumes of pointed corrosion on the metal surface of the pipeline or the fittings which do not lead to considerable leakages of the heat carrier and do not reduce the mode of its transportation. However, there is the damage to the environment and the applied methods of diagnostics have to fix this condition, which forecast of development is obviously accompanied by environmental risks. faulty condition of the heating system can take place, in more serious cases, such as violations of heat-insulating and waterproofing layers of the pipeline, partial destruction of seams of reinforced concrete structures of channels and chambers, flooding, etc., which also have to be differentiated by the methods of diagnostics of technical condition during monitoring of the economy of HSO. But at the same time the heating system is efficient as it performs its main function (the transfer of heat).

Information on the actual state of engineering systems which will allow in the course of adoption of managerial decisions to range the heating systems under maintenance according to their states to requirements of reliable heat supply of consumers of the city has to become the result of diagnostics primary character. The distribution of damages of heating systems from external and internal corrosion depending on types according to the constructive decisions was considered [7, 8] (Table 1).

Table 1. Distribution of damages of the heating systems because of corrosion.

\begin{tabular}{|l|l|l|l|l|}
\hline $\begin{array}{c}\text { Type of } \\
\text { constructive } \\
\text { decisions }\end{array}$ & $\begin{array}{c}\text { Impassable } \\
\text { channel }\end{array}$ & $\begin{array}{c}\text { Semi-passable } \\
\text { channel }\end{array}$ & $\begin{array}{c}\text { Channelless in } \\
\text { foam- } \\
\text { polyurethane }\end{array}$ & $\begin{array}{c}\text { Channelless } \\
\text { in reinforced } \\
\text { foam- } \\
\text { concrete }\end{array}$ \\
\hline \multicolumn{5}{|c|}{ External corrosion , \% } \\
\hline Fistulas & 86 & 85 & 80 & 69 \\
\hline Gaps & 13.9 & 14.8 & 20 & 31 \\
\hline $\begin{array}{l}\text { Cracks of a } \\
\text { welded seam }\end{array}$ & 0.1 & 0.2 & - & - \\
\hline \multicolumn{5}{|l|}{ Internal corrosion, $\%$} \\
\hline Fistulas & 92 & 88 & 76 & 67 \\
\hline Gaps & 7.4 & 10.6 & 17 & 1 \\
\hline $\begin{array}{l}\text { Cracks of a } \\
\text { welded seam }\end{array}$ & 0.2 & 1.4 & 7 & 32 \\
\hline
\end{tabular}

As a result of this analysis there is the possibility of creation of statistical information support of heating systems maintenance management as the set of the qualifiers (for the reasons, by types of damages) reflecting characteristics of heating systems which will provide exact and unambiguous assessment of their performance.

\section{Results}


The use of the aforesaid materials in combination with the analysis of experience of the organization of information support of management of heating systems maintenance by domestic heat supplying organizations, allowed to obtained some results of reengineering. Nowadays any final system decisions on the organization of diagnostics of heating systems on the basis of the scientifically based principles and criteria are not received, however some developments are presented in open access sources $[10,11]$. Formation of provisions on the choice of concrete methods and technical means of diagnostics was not included into the problems this research. However, at this stage of studying of the directions of improvement of heat supply technologies, including auxiliary technology of diagnostics, the engineering systems of the city allowing to predict reliability, thanks to the obtained quantitative data and priorities revealed, the following statements were offered:

1. for the corrosion reasons:

- the methods allowing to fix local thinning of pipelines walls in the form of ulcers from external and internal corrosion are most relevant;

- application of the methods, revealing presence of corrosion factors is necessary (including presence of water in the canal, the humidity of isolation increased thermal losses on the site, presence of electrical potential pipe-earth, sites with the raised tensely deformed state, etc.);

2. for not corrosion reasons

- the methods, providing check of observance of requirements to welded connections of heating systems pipelines and revealing defects are priority it is much less than engineering systems, allowed by normative and technical documents as well as by maintenance documents [12];

- the methods defining existence of violations of compensation of thermal expansion of pipes (cracks and ruptures of a welded seam and mechanical deformations of pipes).

Now a considerable arsenal of technical means of diagnostics of the heating systems condition is created. The specifics of the Russian heating systems (the high accident rate) promoted emergence of various technical means of diagnostics, which exceed similar developments in other countries, owing to much smaller demand in the conditions of the minimum accident rate of engineering systems. At the same time a variety of constructive decisions of the heating systems under maintenance, demands individual approach during the choice of the diagnostics methods, allowing to define reliability of engineering systems maintenance in the city, taking into account the design features of sites of engineering systems, criticality of the predicted and recorded damages, as well as the cost and reliability of the methods planned to application.

Acknowledging the possibility and objective necessity of holding further discussions in process of improvement of methods of diagnostics including in the context of reengineering in $\mathrm{HSO}$, we will note that the interesting developments of structure of information support which are the most preceding our work, is the information exchange of divisions and employees of HSO during the heating systems maintenance the developments of the "Sherna" company, presented in the document "Technique of Technical Diagnosing of Pipelines for Hot Water of Category IV" (according to the application by Federal Service for Environmental, Technological and Nuclear Supervision. Letter 09-03-06/3123 dated 07.06.2013) [1- the set of the qualifiers, presenting the characteristics of heating systems, including connected with the existence of various type of risks of negative impacts on the urban environment which are used by one and all structural divisions of the organization, regardless of the functionality, which is carried out by them, is being formed. The specifics of heating systems as industrially dangerous engineering object define the following structure of qualifiers: elements by types of constructive decisions, territories of dislocation of heating systems, the list of corrosion and non-corrosion reasons of changes of technical conditions of heating systems, the list of defects of the heating systems, interfaced to various risks, 
potential damages at negative impact on the environment in the city. According to preliminary estimates the listed positions of qualifiers can contain up to 50 - 100 separate units of account as a part of primary character of information on actual state of engineering systems;

- there are accepted rules of identification of sites of heating systems with unambiguously determined parameters for the whole economy of HSO, to which the binding of data is made. These data were found out during maintenance or on the basis of application of methods of diagnostics of heating systems conditions for assessment of possibility of various risks differentiated on importance degree;

- the certain technique of assessment of thermal losses on the site of heating systems, used for data processing after diagnostics is accepted. Definition of thermal losses in HSO, comparison them with the thermal losses allowed by normative and technical documents is worked methodically rather well out [13]. Thermal losses are determined or in general by all heat-supply economy, or by separate system. At management of heating system site maintenance existence of the factors provoking development of corrosion processes, the main one is the contact of water with metal of the heating system pipeline is taken into account;

- the list of forms of data presentation with instructions for their filling which are intended for the use by certain specialists of structural divisions of HSO is established. That is also proper for the forms, created according to the results of diagnostics. The example of a form for representation of results of diagnostics of temperature is given below (Table 2). The new principle of further use of these forms is important - for each heating system site section they are integrated into one form, containing all the information, which is available for HSO. The form visually represents all the aspects of operation of engineering systems, essential for management. The analysis of this development, along with the publications of other authors on this subject, has allowed us to create the following positions defining changes in the substantial characteristic of information support of management formed "from scratch" [14]:

Table 2. Example of the form for presentation of the results of diagnostics (the protocol of temperature measurement).

\begin{tabular}{|c|c|c|c|c|c|c|c|}
\hline \multicolumn{3}{|c|}{ Site for control } & \multicolumn{5}{|c|}{ K 221-K222 } \\
\hline \multicolumn{3}{|c|}{ Date of control } & \multicolumn{5}{|c|}{15.01 .2018} \\
\hline \multicolumn{3}{|c|}{ Temperature of external area } & \multicolumn{5}{|l|}{$5^{\circ} \mathrm{C}$} \\
\hline \multicolumn{3}{|c|}{ Temperature of the heat carrier } & \multicolumn{5}{|c|}{$\begin{array}{l}\text { Giving } 75^{\circ} \mathrm{C} \\
\text { Return } 40^{\circ} \mathrm{C}\end{array}$} \\
\hline \multicolumn{3}{|c|}{ Technical means of diagnostics } & \multicolumn{5}{|c|}{ Superficial thermometer $\langle\mathrm{XXX} »$} \\
\hline \multirow[b]{2}{*}{$\begin{array}{l}\text { Point of } \\
\text { access }\end{array}$} & \multirow[b]{2}{*}{$\begin{array}{l}\text { Type } \\
\text { of the } \\
\text { pipelin } \\
\text { e of the } \\
\text { heating } \\
\text { system }\end{array}$} & \multirow[b]{2}{*}{$\begin{array}{c}\text { diameter } \\
, \mathrm{mm}\end{array}$} & \multirow{2}{*}{$\begin{array}{c}\text { Sizes of } \\
\text { the } \\
\text { channel } \\
\text { in w } \\
\text { width, } \\
\text { m and } \\
\text { h height, } \\
\text { m } \\
\text { w x h }\end{array}$} & \multirow{2}{*}{$\begin{array}{l}\text { Laying } \\
\text { depth } \\
\text { (up to } \\
\text { the } \\
\text { pipes } \\
\text { axis) } \\
\text { h, mm }\end{array}$} & \multirow{2}{*}{$\begin{array}{l}\text { Distanc } \\
\mathrm{e} \\
\text { betwee } \\
\mathrm{n} \text { the } \\
\text { pipes } \\
\text { axes } \mathrm{P} \\
\text { and } \mathrm{O}, \\
\mathrm{mm}\end{array}$} & \multicolumn{2}{|c|}{$\begin{array}{l}\text { Air temperature in the } \\
\text { channel, }{ }^{\circ} \mathrm{C}\end{array}$} \\
\hline & & & & & & $\begin{array}{l}\text { Temperatur } \\
\mathrm{e} \text { in the } \\
\text { point of } \\
\text { access } \\
{ }^{\circ} \mathrm{C}\end{array}$ & $\begin{array}{c}\text { Temperat } \\
\text { ure, } \\
\text { average } \\
\text { for the } \\
\text { site } \mathrm{t}_{\mathrm{a}}^{\circ} \mathrm{C}\end{array}$ \\
\hline beginning & direct & 700 & $2,5 \times 1,2$ & 2000 & 1200 & 50 & \multirow{4}{*}{52.5} \\
\hline beginning & Return & 700 & $2,5 \times 1,2$ & 2000 & 1200 & 50 & \\
\hline end & direct & 700 & $2,5 \times 1,2$ & 2150 & \multirow{2}{*}{1200} & \multirow{2}{*}{55} & \\
\hline end & Return & 700 & $2,5 \times 1,2$ & 2150 & & & \\
\hline
\end{tabular}


Nowadays any final system decisions on the organization of diagnostics of the heating systems on the base of the scientific principles and criteria are not received, however the some developments, are presented by open sources [15]. Going on our research in this area, the authors have received the certain results, promoting the improvement of diagnostics, regarding formation of the conditions for the use of methods of diagnostics. In the core of the choice of methods of diagnostics the analysis of the causes and the nature of the environmental risks, connected with changes of technical condition of the heating systems should present. for the definition of the most characteristic causes, which need to be revealed by the methods of diagnostics of technical condition The analysis of ten-year statistics of damages of the high-level heating systems has been carried out, for the definition of the most characteristic causes, which need to be revealed by the methods of diagnostics of technical condition.

The basic provisions of formation of information on sites of heating systems as a part of monitoring, used in the system of ecological management, have to make up the following system (Figure 2):

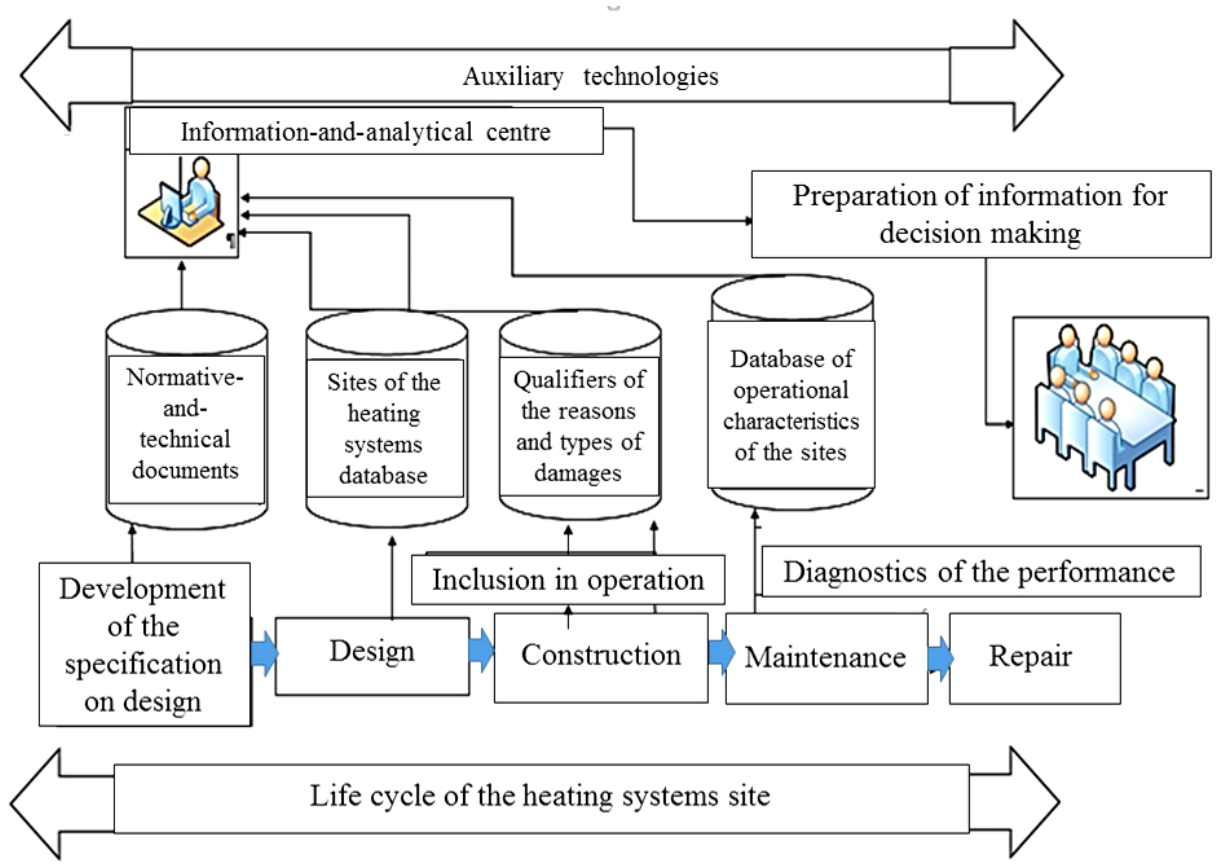

Fig. 1. Main components of information support heating systems maintenance management on the basis of reengineering measures.

The given results allowed to receive a new basis for the heating systems maintenance management, for planning of repairs of the engineering systems having the most significant effect on the urban environment and acting as mainly negative factor of development of the city. The analytical dependences based on a concept of "a residual resource" which according to provisions of the specifications and technical documentation is defined as "a total operating time of an object from the moment of control of its technical condition until achievement of a limit state" are given below. The residual resource is considered in relation to the most subject to damages to operation of a constructive part - to the pipeline of heating systems $[21,22]$. The residual resource of pipelines at an operational phase $[\mathrm{T}]$ is defined by calculation and comparison of three indicators:

$$
[\mathrm{T}]=\min \left([\mathrm{T}]_{\eta},[\mathrm{T}]_{\mathrm{c}},[\mathrm{T}]_{\theta}\right),
$$

where $[\mathrm{T}]_{\eta}$ - residual resource of pipelines on cyclic durability; 
$[\mathrm{T}]_{\mathrm{c}}$ - residual settlement resource of pipelines on corrosion wear;

$[\mathrm{T}]_{\theta}$ - residual settlement resource of pipelines on economic feasibility.

The residual resource of pipelines on cyclic durability $[\mathrm{T}] \eta$ is calculated as:

$$
\mathrm{T}_{\eta}=\frac{\left[\mathrm{N}_{\mathrm{c}}\right]}{\mathrm{N}_{\mathrm{c}}}-\tau
$$

where $\left[\mathrm{N}_{\mathrm{c}}\right]$ - the admissible number of full cycles of loading of the pipeline according to standards;

$\mathrm{N}_{\mathrm{c}}$ - the settlement number of full cycles of loading per one year of continuous maintenance of the pipeline of the heating system according to standards;

$\tau$ - operating time of the pipeline of the heating system at the moment of the last diagnosing.

The residual resource $[\mathrm{T}] \mathrm{c}$ for corrosion wear of pipelines is calculated as:

$$
\left[\mathrm{T}_{\mathrm{c}}\right]=\frac{\mathrm{s}_{\mathrm{f}}-\mathrm{s}_{\mathrm{R}}}{\mathrm{a}}
$$

where a- speed of uniform corrosion (erosive wear), mm per year;

$\mathrm{s}_{\mathrm{f}}-$ minimum actual thickness of a wall of a pipe, $\mathrm{mm}$;

$\mathrm{S}_{\mathrm{R}}$ - settlement thickness of the wall element, $\mathrm{mm}$;

Speed of uniform corrosion a is calculated as:

$$
\mathrm{a}=\frac{\mathrm{s}-\mathrm{S}_{\mathrm{f}}}{\tau},
$$

where $\mathrm{s}_{\mathrm{f}^{-}}$nominal thickness of the pipeline wall, $\mathrm{mm}$.

Settlement thickness of the pipe wall $S_{R}$ is calculated as:

$$
\mathrm{S}_{\mathrm{R}}=\frac{|\mathrm{p}| \cdot \mathrm{D}_{\mathrm{a}}}{2 \cdot \varphi_{\mathrm{y}} \cdot[\sigma]+|\mathrm{p}|},
$$

where $\mathrm{p}$ - internal excessive pressure in the pipeline, $\mathrm{MPa}$;

$D_{a}$ - outer diameter of a pipe, $\mathrm{mm}$;

$\varphi_{\mathrm{y}}$ - the coefficient of durability of a longitudinal welded seam during stretching according to standards;

$[\sigma]$ - allowable stress, $\mathrm{MPa}$.

Allowable stress $[\sigma]$ is calculated as:

$$
[\sigma]=\min \left(\frac{\sigma_{\mathrm{B} / \mathrm{t}}}{2,4} ; \frac{\sigma_{\mathrm{p} / \mathrm{t}}}{1,5}\right)
$$

where $\sigma_{\mathrm{B} / \mathrm{t}}-$ minimum value of strength of the pipe material, $\mathrm{MPa}$;

$\sigma_{\mathrm{p} / \mathrm{t}}-$ minimum value of the fluidity limit for the pipeline, MPa.

Residual resource for economic feasibility $[\mathrm{T}] \theta$ is estimated by the minimum value of the following function:

$$
\mathrm{S}_{\mathrm{y}}\left(\tau+[\mathrm{T}]_{\theta}\right)=\frac{\mathrm{I}\left(\tau+[\mathrm{T}]_{\theta}\right)}{\tau+[\mathrm{T}]_{\theta}} \rightarrow \min
$$

where $I$ - life cycle cost of the pipeline of the heating system, roubles;

$\tau$ - current term of heating system pipeline maintenance, years.

Life cycle cost of of the heating system pipeline:

$$
\mathrm{I}\left(\tau+[\mathrm{T}]_{\theta}\right)=\mathrm{C}+\mathrm{M}\left(\tau+[\mathrm{T}]_{\theta}\right),
$$

where $\mathrm{C}-$ the expenses on the creation of the pipeline including costs of its design and construction;

$$
M(t)=M_{m}(t)+M_{1}(t)-\text { running costs; }
$$


$\mathrm{M}_{\mathrm{m}}(\mathrm{t})$ - direct cost on ensuring of the heating system pipeline maintenance, including costs of diagnostics and repair;

$\mathrm{M}_{1}(\mathrm{t})$ - the additional expenses caused, by need of insurance of operational risks or different direct compensation of the damages arising in case of possible development of accidents on the heating system pipeline.

Direct cost of ensuring of the pipeline maintenance $\mathrm{M}_{\mathrm{m}}(\mathrm{t})$ is calculated as:

$$
M_{m}(t)=S_{D}{ }^{\mathrm{L}} * \sum_{i=0}^{t} \mu_{1}(i)+S_{D}{ }^{\mathrm{s}}-\sum_{i=0}^{t} \mu_{2}+S_{D}^{T O} * t
$$

where $\mathrm{t}$ - term, years;

$\mathrm{S}_{\mathrm{D}}{ }^{\mathrm{L}}$ - average cost of the local recovering repair of the elementary section of the heating system pipeline, roubles;

$\mathrm{S}_{\mathrm{D}} \mathrm{S}$ - the average cost of a hole, roubles at the heating system pipeline (for elevated laying and passable channels);

$\mathrm{S}_{\mathrm{D}} \mathrm{S}=0$

$\mathrm{S}_{\mathrm{D}}{ }^{\mathrm{TO}}$ - average cost of annual maintenance of the heating system pipeline, roubles;

$\tilde{\mu}_{1}(t)$ - parameter of the stream of damages (gaps) which is equal to the predicted number of refusals of this view of the reconstructed site in the year calculated on the basis of data of information support of maintenance management.

$\mu_{2}(t)$ - parameter of the stream of refusals fistulas, which is equal to the predicted number of refusals (fistulas) of the reconstructed site per year, calculated on the basis of data of information support of maintenance management.

Additional costs $\mathrm{M}_{1}(\mathrm{t})$ are calculated:

$$
M_{l}(t)=\sum_{j} \Delta U_{j} * \sum_{i=0}^{t} \tilde{\mu}_{j}(i)
$$

where $\tilde{\mu}_{j}(t)$ - parameter of the stream of refusals which is equal to the predicted number of refusals of the reconstructed site in the year calculated according actual standards;

$\Delta U_{j}$ - criticality of refusal of the concrete site of heating system.

Coming back to the initial formula (1) we can note that the decision, which is being made has complex character which considers requirements of standard-and-technical documents, the speed of action of corrosion factors because of the features of life cycle installed earlier of engineering systems and also economic indicators which earlier relatively were seldom taken into consideration in comparison with technical parameters.

\section{Discussion}

The aforesaid provisions on fundamental reconsideration of information support of management of the heating systems maintenance of the city HSO on the basis of provisions of reengineering, allows to mark out for further discussions the gained effects and administrative situations of application of offers in development of the modern city in various temporary horizons. System representation of features of information support in management of modern HSO, essential to development of the city, is presented in Figure 2. 


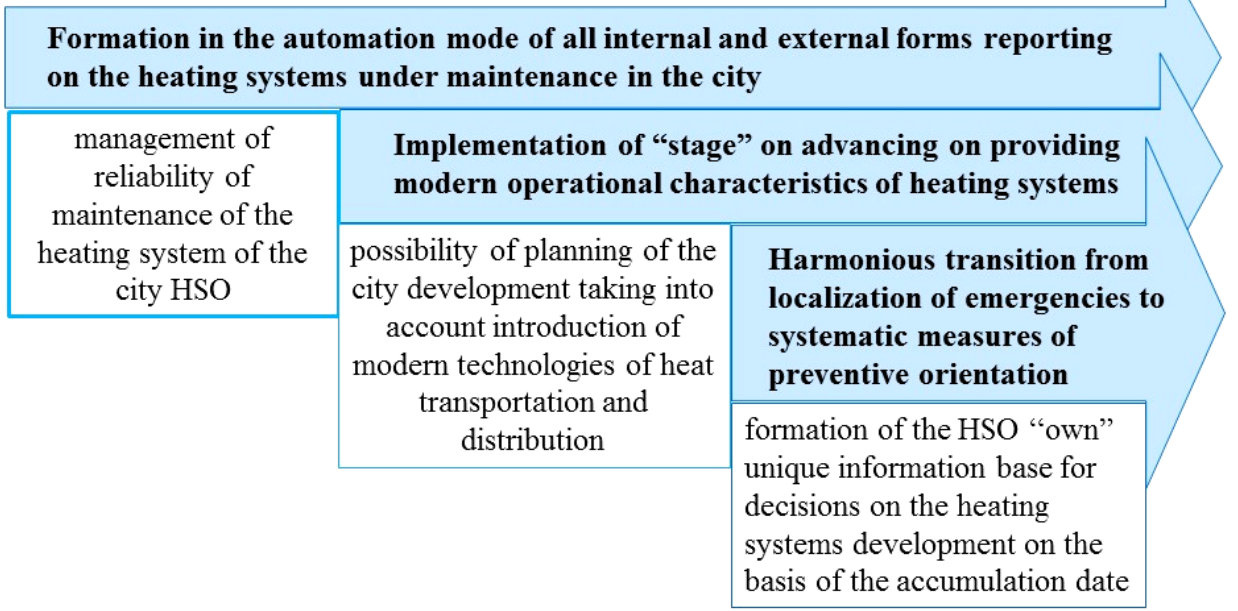

Fig. 2. Changes in HSO management during redesign of information support of management of heating systems maintenance in the city on the basis of provisions of reengineering.

We will submit scenarios in the direction of decrease in positive estimates of opportunities for scientific technological development and corresponding changes in management of HSO [16].

The first scenario is "power revolution" which consists in withdrawal from hydrocarbonic sources, development and deployment of new technologies for use of renewables. In the context of this scenario, changes not so much of technologies of heat supply and processes of management of operation how many change of approaches to resource supply of the cities in general that will lead to essential transformations of the organizations which are carrying out their delivery are possible.

The second scenario submitted as optimum is "the formation of a new era of hydrocarbons" at which for "oil" in world power there will be conditions of simultaneous growth and demand, and the price at the expense of the accelerated growth of world economy (it isn't lower than 3,5\% in a year) and possible reduction of potential of oil production which reasons aren't detailed. The sharp need for reengineering for the estimated prospect can not arise in the context of this scenario, gradual managements of TSO of improvement can be quite justified.

The third scenario is "the era of low prices of hydrocarbons" which is based on preservation of unfortunate price trends concerning these products. In the context of this scenario reengineering which and in addition to development of technologies will provide to a dress high-quality breakthrough in HSO control system in the estimated prospect is modern.

\section{Conclusion}

In the this article the attempt to define some opportunities and the prospects of application of reengineering in practice of management of rather conservative part of the modern city (heat supplying organizations), which management does not demonstrate high susceptibility to innovations is made. However, the incentives which are objectively result in changes in the technical sphere inevitably involve also in the sphere of management. But Information support as the area, allocated for reengineering as the initial measure in this direction - is rather important for holding the actions for reengineering positioned by authors from positions of obtaining desirable result of increase in efficiency of planning of urban 
development. The received results and offers allow to rationalize horizontal communications in management, to provide the possibility of decision-making by managers in the independent mode due to existence of reliable information for these actions and also creates basis for the subsequent positive changes.

\section{References}

1. N. Verstina, A. Goncharov, E. Evseev, Economy: yesterday, today, tomorrow 4, 42-54 (2016)

2. N. Verstina, E. Akimova, T. Blinova, Real estate: economy, management 3, 42-47 (2015)

3. N. Verstina, T. Meshcheryakova, MATEC Web of Conferences 73 (2016)

4. T. Meshcheryakova , N. Verstina, Advances in Intelligent systems and computing 692, 1136-1150 (2018)

5. T. Verminskaya, V. Zinatullin, A. Kuhta, I. Rubtsov, E. Chibisova, Almanac of modern science and education 7, 37-39 (2008)

6. A.A. Krygin, Automatic equipment and telemechanics 9, 83-102 (2010)

7. T. Blinova, MATEC Web of Conferences 73 (2016)

8. N. Verstina, E. Evseev, Advances in Intelligent systems and computing 692, 1125-1135 (2018)

9. R. Dylewski, J. Adamczyk, Energy and Buildings 54, 88-95 (2012)

10. A. Skvortsov, S. Slyusarenko, S. Subbotin, V. Dmitriyenko, A. Kobrin, Information support of engineering systems, https://elibrary.ru/item.asp? id=22426691/// (2018)

11. E. Gumerova, O. Gamayunova, T. Meshcheryakova, Advances in Intelligent Systems and Computing 692, 432-439 (2018)

12. M. Tyre. RES POLICY 20-1, 57-76 (1991)

13. A. Mottaeva, A. Minnullina, IOP Conference Series: Earth and Environmental Science 90 (1), 012123 (2017)

14. M.A. Bahauovna, M.A. Bahauovna, International Journal of Applied Engineering Research 10(23), 43446-43449 (2015)

15. N. Verstina, T. Meshcheryakova, Biosciences biotechnology research Asia 12 (2), 1411$1423(2015)$

16. T. Meshcheriakova, MATEC 106, 06021 (2017) 